\title{
Рудно-геохимическая зональность эндогенных рудных месторождений как следствие распространённости, периодичности и термодинамических свойств элементов
}

\author{
А.В. Кокин \\ Южно-Российский институт управления Российской академии народного \\ хозяйства и государственной службы при Президенте РФ, 344000, Ростов- \\ на-Дону, ул. Пушкинская, 70. E-mail: alex@avkokin.ru \\ (Статья поступила в редакцию 4 апреля 2015 г.)
}

Исследована рудно-геохимическая зональность эндогенных рудных месторождений Северо-Востока РФ. Установлено, что пространственно-временная зональность полигенных и полихронных месторождений может формироваться по правилу прямой или обратной стадийной зональности и подчиняется распространённости элементов на Солнце, в хондритах, земной коре. Последовательность элементов в ряду зональности сохраняется на уровне состава руд и примесей в минералах. На основе выделения частных рядов зональности в структурах эмпирически установленных обобщённых рядов по месторождениям может быть решена прямая и обратная задачи наличия или отсутствия наложенных процессов рудообразования, а также участия в нём разных источников металлов.

Ключевые слова: эндогенные месторождения, зональность рудно-геохимическая, минеральные стадии, примеси в минералах, распространённость элементов, стандартная энтропия, Солнце, хондриты, земная кора.

DOI: $10.17072 /$ psu.geol.28.43

\section{Постановка проблемы}

В рудообразовании полигенных и полихронных месторождений, как известно, участвуют разные источники вещества, в том числе рудовмещающая среда [11], а минералообразование может происходить в условиях формирования прогрессивной или регрессивной зональности [16]. Это может сопровождаться пространственным совмещением различных по времени минеральных стадий и источников рудообразования на фоне усложнения геологической структуры и несомненно скажется на закономерности распределения элементов в составе рудных тел месторождений (зональности), поскольку каждая стадия ха- рактеризуется присущей ей ассоциацией элементов. Уповать на «универсальные» ряды геохимической зональности опасно, поскольку таковые являются статистическими и не могут учитывать конкретную историю развития как самой геологической структуры, так и полистадийного рудообразования $[1,10]$.

\section{Цель исследования}

Заключается в попытке найти общие закономерности при формировании зональности эндогенных рудных месторождений. Для этого в рамках принципа Ле Шателье-Бруна, первого и второго начала термодинамики была выдвинута гипоте- 
за: если система, сформированная в одну стадию рудообразования, перешла в устойчивое равновесие с окружающей средой, а с течением времени оказалась выведенной из него под влиянием какихлибо РТС-условий, то в ней возникнут процессы, направленные на компенсацию этого воздействия, и она перейдёт в иное состояние, которое можно зафиксировать не только в изменении состава руд и минералов, но и в рудно-геохимической зональности.

Поскольку рудно-геохимическая зональность рассчитывается на основе валовой оценки коэффициентов накопления элементов по падению или восстанию рудных тел, то, возможно, в одном сечении рудного тела могут быть зафиксированы аномально высокие концентрации элемента, участвующего в формировании геохимических ассоциаций нескольких стадий, а в другом - аномально низкие, но соответствующие верхнерудному сечению основной продуктивной стадии. В этом смысле рассчитанный ряд зональности нельзя использовать для достоверной оценки уровня вскрытия месторождения по тому или иному металлу, равно как по выбору надрудной и нижнерудной ассоциаций.

Но если в эмпирически установленном ряду рудно-геохимической зональности месторождения переранжировать элементы каким-либо другим способом, но отвечающим их фундаментальным свойствам, то возможны следствия. Например, если структура последовательности элементов в эмпирическом ряду зональности при таком ранжировании не нарушится, значит, рудное тело и зональность сформировались в одну стадию, из одного источника и никогда не подвергались каким-либо внешним воздействиям. Если структура зонального ряда изменится, то рудообразование происходило с участием различных источников и во столько стадий, сколько разрывов наблюдается в составе обобщённого эмпирического ряда зональности.

К фундаментальным свойствам хими- ческих элементов можно отнести величину их стандартной термодинамической энтропии, характеризующей меру необратимой диссипации энергии и относительную распространённость элементов разных уровней организации вещества (кларки), значение величины которых не всегда удаётся установить с необходимой точностью $[6,15]$.

\section{Методика и объекты исследований}

Методика включает в себя выделение пространственно-временных стадий в рудообразовании и участие рудогенных элементов в формировании геохимической зональности в различных минеральных типах рудных месторождений; сравнение рудно-геохимической зональности с таковой, но рассчитанной по примесям минералов; исследование соответствия положения элементов в эмпирических рядах рудно-геохимической зональности с рядами, ранжированными по величине стандартной энтропии и относительной распространённости их в Солнечной системе, хондритах, земной коре.

Объекты исследований: золоторудные, полиметаллические, оловосеребряные проявления и месторождения, проявление марганцево-сульфидных (алабандиновых) руд в Восточной Якутии, золотосеребряная минерализация Северного Приохотья.

\section{Процедура построения рядов рудно- геохимической зональности}

Под рудно-геохимической зональностью автор понимает пространственную (вертикальную, латеральную, по направлению разгрузки рудообразующих растворов или склонению рудной минерализации в рудных телах) закономерность распределения только тех химических элементов в составе рудной массы, которые непосредственно связаны с процессом рудообразования. Это означает, что в состав зональных рядов не должны включаться элементы, не связанные с формированием pyd, поскольку геолога-практика прежде всего интересует закономерность пространственного распределения непосред- 
ственно рудогенных элементов в рудных телах, которые представляют интерес для оценки степени вскрытия оруденения на тот или иной комплекс металлов [2].

Для того чтобы быть уверенным в том, что построенный ряд рудно-геохимической зональности отражает действительное состояние закономерного пространственного распределения химических элементов в рудном теле (месторождении) необходимо (минимум) иметь: данные об этапности, стадийности минералообразования в составе руд месторождения; представление о пространственном совмещении или разобщении минеральных стадий по времени их образования и о том, с какой минеральной стадией (стадиями) связан(ы) искомый(е) элемент(ы), интересующий(е) геолога-практика, в какой части рудной колонны (низ, верх) он может образовывать максимальные концентрации; возможность выделить основные минералы-носители главных рудных и примесных элементов в стадиях рудообразования, которые могут составлять ряд рудно-геохимической зональности.

Методика составления обобщённых (эмпирических) рядов рудногеохимической зональности основывалась на сведении материалов по разрозненным сечениям опробования руд и на анализе примесей сквозных минералов рудообразования в этих же сечениях.

\section{Обсуждение результатов исследования}

В табл. 1 - 4 приведены обобщённые и частные ряды рудно-геохимической зональности различных минеральных типов эндогенных месторождений Восточной Якутии и Северного Приохотья, проранжированные по величине стандартной энтропии $\mathrm{S}_{298}^{0}$, относительной распространённости элементов на Солнце, в хондритах и земной коре.

Обобщённые (эмпирически установленные) ряды рудно-геохимической зональности исследуемых эндогенных месторождений приведены ниже. Ряды 1 - 7 рассчитаны по рудным сечениям месторождений, а 1.1 - $\mathbf{7 . 1}$ - соответственно по примесям в минералах этих месторождений. Стрелкой обозначены векторы вертикальной зональности от нижних к верхним структурно-гипсометрическим уровням. Жирным шрифтом выделены главные рудогенные элементы месторождений.

$$
\begin{aligned}
& \text { 1. } \rightarrow(B i)-\boldsymbol{A u}-\mathrm{Sb}-W-\boldsymbol{A s}-\mathrm{Co}-\mathrm{Ni}-\mathrm{Mn}-\mathrm{Zn}-\mathrm{Cu}-\mathrm{Pb}-\mathbf{A g} \\
& \mathbf{1 . 1} \rightarrow(B i)-\boldsymbol{A u}-\mathrm{Sb}-\boldsymbol{A s}-\mathrm{Co}-\mathrm{Ni}-\mathrm{Mn}-\mathrm{Zn}-\mathrm{Cu}-\mathrm{Pb}-\mathbf{A g} \\
& \text { 2. } \rightarrow(M o)-W-(S n)-A u, T e, B i-A s-C o-N i \\
& \text { 2.1. } \rightarrow \boldsymbol{B i}-\boldsymbol{A u}-(\mathrm{Sb}, \mathrm{Ag})-\mathrm{Co}-\mathrm{Ni}-\mathrm{Pb}-\mathrm{Cu}-\mathrm{Zn} \\
& \text { 3. } \rightarrow B i-S n-A s-C o-N i-M n-C u-Z n-P b-S b-A g-I n \\
& \text { 3.1. } \rightarrow B i-S n-C o-N i-C u-Z n-P b-I n-A g-S b \\
& \text { 4. } \rightarrow \mathbf{Z n}-\mathrm{Cu}-\boldsymbol{P b}-\mathrm{Sn}-\mathbf{G e}-\mathrm{Sb}-\mathbf{A g} \text {. } \\
& \text { 4.1 } \rightarrow(A s, C o, N i)-M n-C u-Z n-P b-S n-(G e)-S b-\boldsymbol{A g} \\
& \text { 5. } \rightarrow M n-C u-Z n-P b-G e-A g-(C d)-(H g) \\
& 5.1 \mathrm{Mn}-\mathrm{Cu}-\mathrm{Pb}-\mathrm{Ge}-\mathrm{Ag}-\mathrm{Cd}-(\mathrm{Hg}) \\
& \text { 6. } \rightarrow \mathrm{Zn}-\mathrm{Pb}-\boldsymbol{A u}-\mathbf{A g}-\mathrm{As}-\mathrm{Sb}-(\mathrm{Hg}) \\
& 6.1 \rightarrow A s-S b-A g-A u \\
& \text { 7. } \rightarrow A s-C o-N i-C u-Z n-S n-P b-M n-S b-A g-I n \\
& \text { 7.1 } \rightarrow A s-C o-N i-C u-G a-Z n-S n-P b-S b-A g-C d, I n
\end{aligned}
$$

Подробно процедуру выделения частных рядов и выявления её стадийности на основе обобщённой рудно-геохимической зональности рассмотрим только на трёх примерах, а расчёты для остальных объектов отразим в табл. $1-4$. 
Зональность полистадийной и полигенной золоторудной минерализации (ряды 1 и 1.1 табл. 1) Нежданинского золоторудного месторождения в Восточной Якутии [5]. Оно представляет собой минерализованные зоны дробления и золотокварцевые жилы. Сформировалось среди обогащённой золотом (до 7 кларков), мышьяком (3 - 10 кларков), свинцом (2 - 5 кларков) рудовмещающей черносланцевой толщи ранней перми в ранний догранитоидный и поздний постгранитоидный $\left(K_{1}-\right.$ $\mathrm{K}_{2}$ ) этапы. С ранним догранитоидным этапом (по данным геологов Н.В. Белозерцевой и М.К. Силичева, впервые установившими эту закономерность на месторождении) связано образование ранней рассеянной золото-пирит-арсенопиритовой минерализации в минерализованных зонах дробления (МЗД). Золото в этой ассоциации находится в связанном состоянии с пиритом и арсенопиритом, концентрации в которых варьируются от 25 до 370 г/т. Со следующим этапом связан процесс нового дробления и перекристаллизации в МЗД раннего пирита и арсенопирита с высвобождением большей части золота в свободном состоянии в кварцевые прожилки МЗД и жилы. Последующие стадии рудообразования наложены на предыдущие. Это халькопирит-галенитсфалеритовая, в которой золото чаще находится в срастании с галенитом и выделяется позже сульфидов стадии. Серебро концентрируется в этой стадии с галенитом и в меньшей степени со сфалеритом. И наконец, серебро-золотосульфоантимонитовая (с наличием в ассоциации преимущественно сульфосолей свинца, серебра, сурьмы). Ближе к корневым фациям оруденения (полностью месторождение по золоту ещё не вскрыто) устанавливаются признаки антимонитовой, золотосульфотеллуридной, шеелитовой минерализации с наличием примесей висмута в рудах при сохранении промышленных концентраций золота. Таким образом, геологи М.К. Силичев и Н.В. Белозерцева устанавливают пять разных по составу стадий минералообразования, хотя и не ис- ключают, что халькопирит-галенитсфалеритовая и сульфоантимонитовая ассоциации представляют собой единую и заключительную золотосеребро-полисульфидную стадию. При этом эволюция источников золота во времени укладывается в схему [9]: золото из вмещающих пород концентрируется вначале в МЗД в составе пирита и арсенопирита (ранняя догранитоидная стадия); в последующую стадию в процессе динамотермального метаморфизма (под влиянием складчатости) пириты и арсенопириты испытывают перекристаллизацию с высвобождением большей части свободного золота в кварцевые прожилки и жилы МЗД; в гранитоидную стадию источником золота могли являться тепловые гидротермальные потоки, пространственно связанные с кислым магматизмом. Таким образом могло формироваться полигенное и полихронное золоторудное Нежданинское месторождение.

Зная общую региональную закономерность пространственного распределения минеральных ассоциаций относительно плутонов в Верхоянской геохимической провинции [11] с переходом золотосульфотеллуридной к антимонитовой, золотопирит-арсенопиритовой, сереброполисульфидной и серебросульфоантимонитовой, можно представить себе гипотетический ряд зональности, который мог бы проявиться на Нежданинском месторождении с учётом тех минеральных и геохимических ассоциаций, какие эмпирически установлены в составе руд месторождения от нижних к верхним гипсометрическим уровням и в направлении от рудогенерирующего плутона. А именно: W, Sb1, Au1, $\mathrm{Bi}$ (золотосульфотеллуридная) - $\mathrm{Au}, \mathrm{As}$, $\mathrm{Co}, \mathrm{Ni}, \mathrm{Mn}$ (золото-пирит-арсенопиритовая) - $\mathrm{Cu}, \mathrm{Zn}, \mathrm{Pb} 1, \mathrm{Ag} 1, \mathrm{Au} 2$ (золотосеребро-полисульфидная) - $\mathrm{Cu}, \mathrm{Zn}, \mathrm{Pb} 2$, $\mathrm{Sb} 2, \mathrm{Ag} 2, \mathrm{Au} 3$ (золотосеребросульфоантимонитовая). Поскольку золото на месторождении установлено во всех минеральных типах (в соответствующей стадии оно выделено порядковым номером в геохимических ассоциациях, в том числе $\mathrm{Sb}$, $\mathrm{Ag}, \mathrm{Pb})$, то это и определило крупные за- 
пасы золота в Нежданинском месторождении.

Располагая данными о составе примесей в минералах рудных стадий [17,11], их можно поместить в ту часть ряда, где находятся их главные минералы-носители. В пирите и арсенопирите это $\mathrm{Co}, \mathrm{Ni}, \mathrm{Au}$, $\mathrm{Pb}, \mathrm{Zn}, \mathrm{Cu}$, редко $\mathrm{Sb}$, незначительные концентрации Ag. В галенитах и сфалеритах тот же набор примесей, исключая $\mathrm{Co}, \mathrm{Ni}$, но с наличием Mn (он преимущественно входит в состав пирита, арсенопирита, а также сфалерита), в сульфоантимонидах $\mathrm{Au}, \mathrm{Pb}, \mathrm{Zn}, \mathrm{Cu}, \mathrm{Sb}, \mathrm{Ag}$. Таким образом, исключив сквозные элементы в минеральных стадиях, кроме золота, серебра и сурьмы, обобщённый ряд пространственной зональности по ассоциациям элементов мог бы выглядеть так: $\mathrm{W}, \mathrm{Bi}, \mathrm{Sb}-\mathrm{Au} 1$, As, Co, Ni, - Mn, Cu, Zn, Pb1, Au2, Ag1 $\mathrm{Au} 3, \mathrm{Sb} 2, \mathrm{Ag} 2$. Ряд оказывается близким к обобщённым эмпирическим рядам (1 и 1.1), построенным по результатам опробования руд и примесям в пирите. Этот факт сам по себе является весьма любопытным. В специфических условиях развития рудно-магматических систем однотипность, направленность рудно-геохимической зональности может проявляться на разном уровне организации геологических тел: региональном (на уровне Верхоянской геохимической провиниии), в составе руд месторождения, в примесном составе минералов. Ниже эту закономерность можно проследить на примере других месторождений провинции (табл. 1 - 4).

Обобщённый ряд рудногеохимической зональности (1) по восстанию рудной зоны №1 установлен по величине коэффициента накопления элементов в интервале 850 м. Стрелкой (здесь и в последующих рядах) показано направление вектора зональности.

Дальнейшая процедура связана с решением задачи построения частных геохимических рядов на основе эмпирически установленной обобщённой зональности по руде (1) и примесям в пирите (1.1). Для этого элементы обобщённых рядов зональности 1 и 1.1 ранжируются по величине стандартной энтропии $\mathrm{S}_{298}^{0}$ (табл. 1). Смысл такого ранжирования заключается в определении направления вектора изменения стандартной энтропии элементов при формировании рудно-геохимической зональности, полагая, что непрерывность рудообразования сопровождается однонаправленным понижением или повышением энтропии в зависимости от регрессивного или прогрессивного процесса, а при участии наложения разных стадий во времени эта однонаправленность может быть нарушена.

Сохраняя эмпирически установленные (снизу-вверх рудной зоны) направления векторов зональности 1 и 1.1, выделим те части рядов, которые подчиняются увеличению или уменьшению значения $\mathbf{S}^{0}{ }_{298}$ элементов. Получаем частный ряд (правая часть табл. 1) ассоциации, согласующийся с эмпирически установленным вектором зональности: $\rightarrow \operatorname{Bi}(56,9)-\boldsymbol{A u}(47,45)$ $S b(42,44)-W(32,76)$. В скобках - значение $\mathrm{S}^{0}{ }_{298}$ элементов. Далее последовательность изменения $\mathrm{S}_{298}^{0}$ в обобщённом ряду прерывается на мышьяке и начиная с него закономерно уменьшается в том же направлении вектора: $\rightarrow A s(35,1)-C o(30,4)-$ $\mathrm{Ni}(29,86)-M n(29,33)$. Продолжая подобную процедуру ранжирования остальной части обобщённого ряда по $\mathrm{S}_{298}^{0}$, заметим, что следующая ассоциация в нём меняет свой вектор изменчивости $\mathrm{S}^{0}{ }_{298}$ на противоположный: $\leftarrow C u(33,3)-Z n(41,9)-$ $A g(42,69)$ - Pbl $(64,9)$. Положение Ag в ряду более чем оправдано, поскольку оно устанавливается в примесях галенита, сфалерита и имеет собственные минералы в составе поздней сульфоантимонитовой ассоциации, которая в обобщённом ряду зональности просто не может быть выделена в силу того, что ряд зональности рассчитывался по коэффициенту валового накопления элементов в рудной зоне. 
Таблица 1. Обобщённые и частные геохимические ряды зональности эндогенных рудных месторождений. Элементы ранжированы по величине (в скобках) стандартной энтропии $S_{298,}^{0}$ дж/моль·град [14]

\begin{tabular}{|c|c|}
\hline Обобщённые ряды геохимической зональности & $\begin{array}{c}\text { Частные ряды геохимической } \\
\text { зональности }\end{array}$ \\
\hline 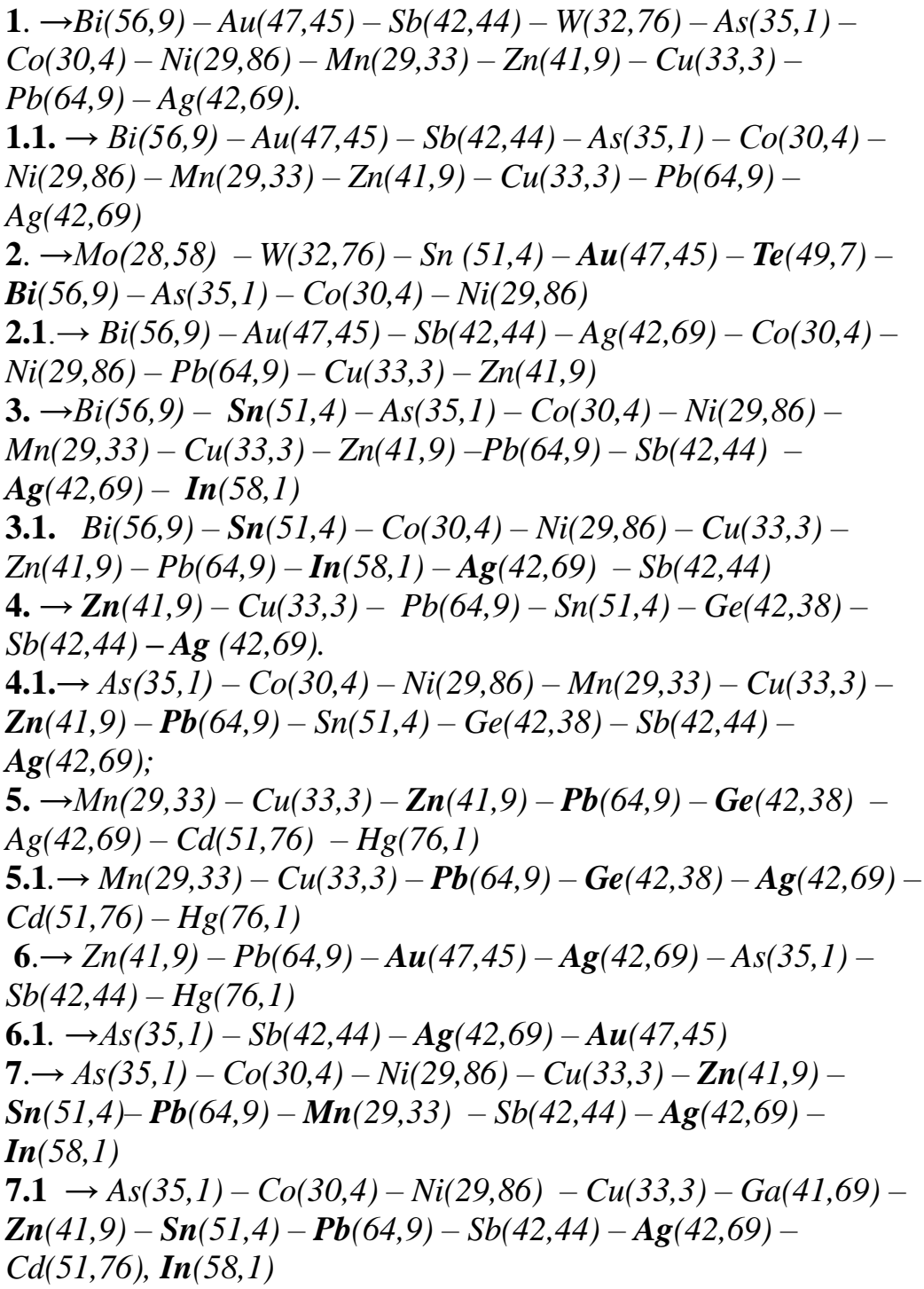 & 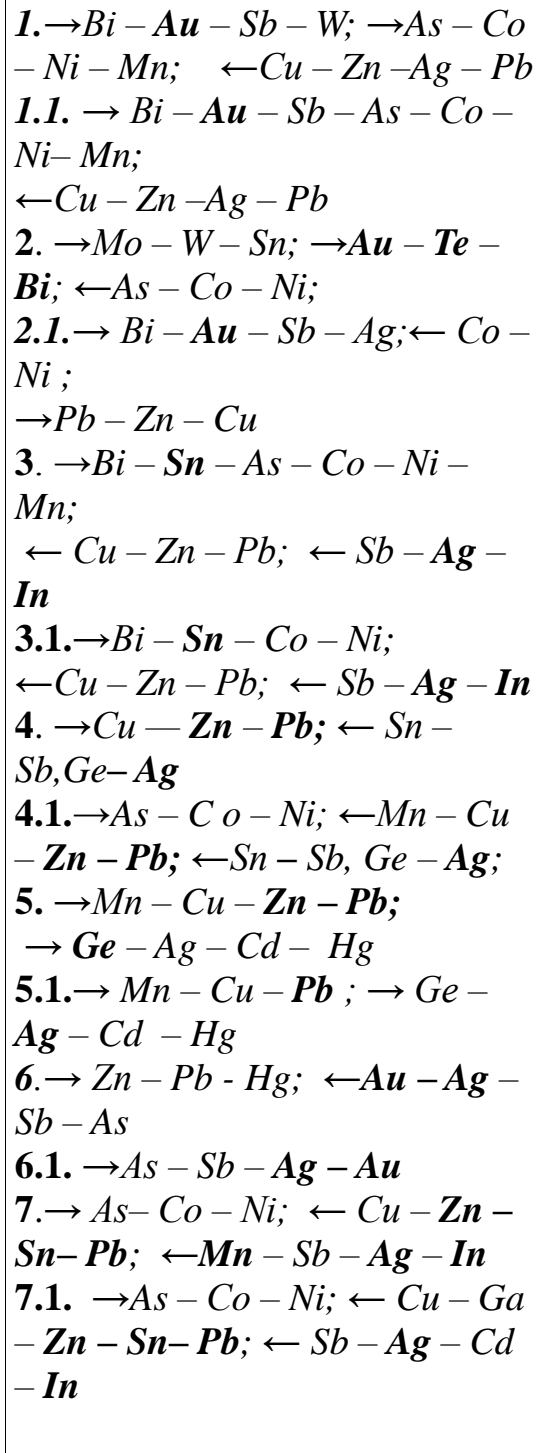 \\
\hline
\end{tabular}

Частные ряды зональности, установленные по примесям в пиритах, отличаются от обобщённого ряда рудногеохимической зональности только тем, что первый и второй ряды по примесям выстраиваются в единый непрерывный ряд изменения $S_{298}^{0}$, а третий - выглядит обратным по отношению к первым.

В рамках принятой гипотезы и процедуры ранжирования обобщённого ряда по $\mathrm{S}^{0}{ }_{298}$ попытаемся восстановить историю формирования геохимических ассоциаций элементов, строго следуя рангам $\mathrm{S}_{298}^{0}$, с привязкой к составу примесей в установленных эмпирически стадиях минералообразования.

Ассоциацию геохимического ряда $\rightarrow$ $\operatorname{Bi}(56,9)-\boldsymbol{A u 1}(47,45)-\operatorname{Sbl}(42,44)-$ $W(32,76)$ оставим без изменения, поскольку ранги элементов соответствуют установленному обобщённому эмпирическому ряду зональности с учтёнными примесями. 
Таблица 2. Обобщённые и частные геохимические ряды зональности эндогенных рудных месторождений.Элементы ранжированы по величине распространённости элементов на Солнце (в скобках) относительно $\mathrm{Si}=10^{6}$ (по Г. Зюсс и Г. Юри [13])

\begin{tabular}{|c|c|}
\hline Обобщённые ряды геохимической зональности & $\begin{array}{c}\text { Частные ряды геохимической } \\
\text { зональности }\end{array}$ \\
\hline 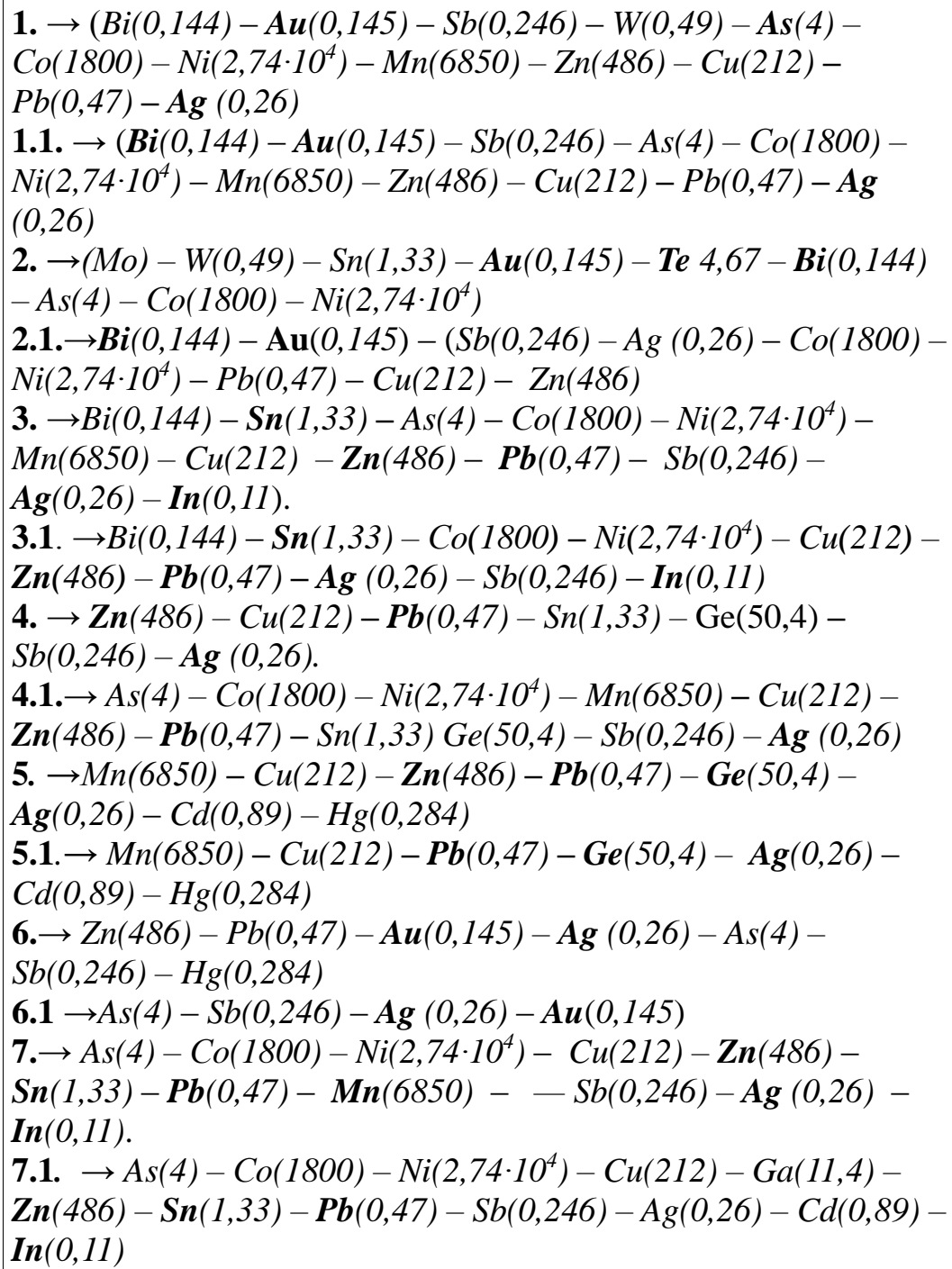 & 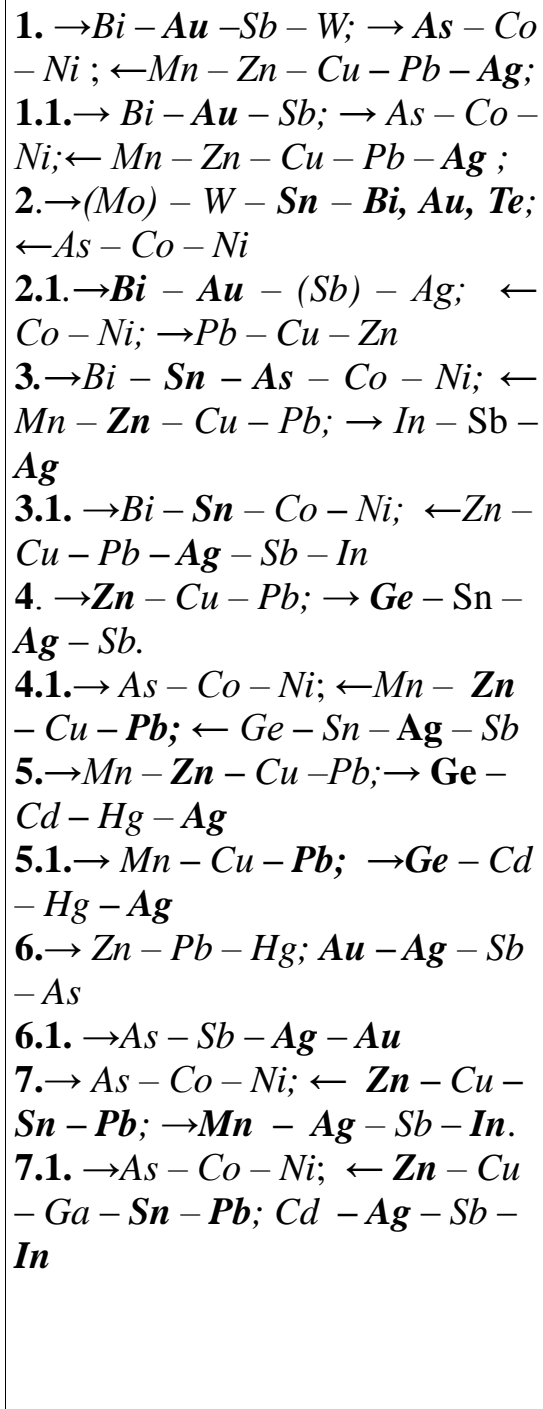 \\
\hline
\end{tabular}

Выделим Au1 и Sb1 порядковыми номерами по принадлежности к первой ассоциации. Тогда к следующей ассоциации необходимо добавить Аu2, потому как As, $\mathrm{Co}, \mathrm{Ni}, \mathrm{Mn}$ в основном концентрируются в золото-пирит-арсенопиритовой ассоциации, содержащей эти элементы. Отсюда ряд этой ассоциации должен быть таким: $\rightarrow \operatorname{Au2}(47,45)-A s(35,1)-\operatorname{Co}(30,4)-$ $\operatorname{Ni}(29,86)-\operatorname{Mn}(29,33)$. Место золота в ряду по величине $\mathrm{S}^{0}{ }_{298}$ может быть определено только перед As. Частный ряд имеет аналогичный по направлению вектор 3ональности, что можно интерпретировать как единонаправленный, но дискретный процесс рудообразования [4], пространственно связанный с единым источником вещества, но с разной подвижностью элементов (чем выше значение $\mathrm{S}_{298}^{0}$ элемента, тем выше способность его к рассеянию). Продолжая подобную процедуру ранжирования остальной части обобщённого ряда по $S^{0}{ }_{298}$, заметим, что следующая ассоциация в нём меняет свой вектор на противоположный относительно первого и второго частных рядов: $\leftarrow C u(33,3)-$ Zn(41,9) - $\boldsymbol{A g} 1(42,69)$ - Pbl (64,9), что можно интерпретировать либо как инвер- 
сию направления рудоотложения под влиянием различных структурнотектонических факторов, либо объяснить влиянием другого источника, например, смешением эндогенного источника с источником металлов вмещающих пород.

Таблица 3. Обобщённые и частные геохимические ряды зональности эндогенных рудных месторождений. Элементы ранжированы по распространённости элементов (в скобках) в хондритах [3], г/m (по А.П. Виноградову, 1962)

\begin{tabular}{|c|c|}
\hline бобщённые ряды геохи & \\
\hline 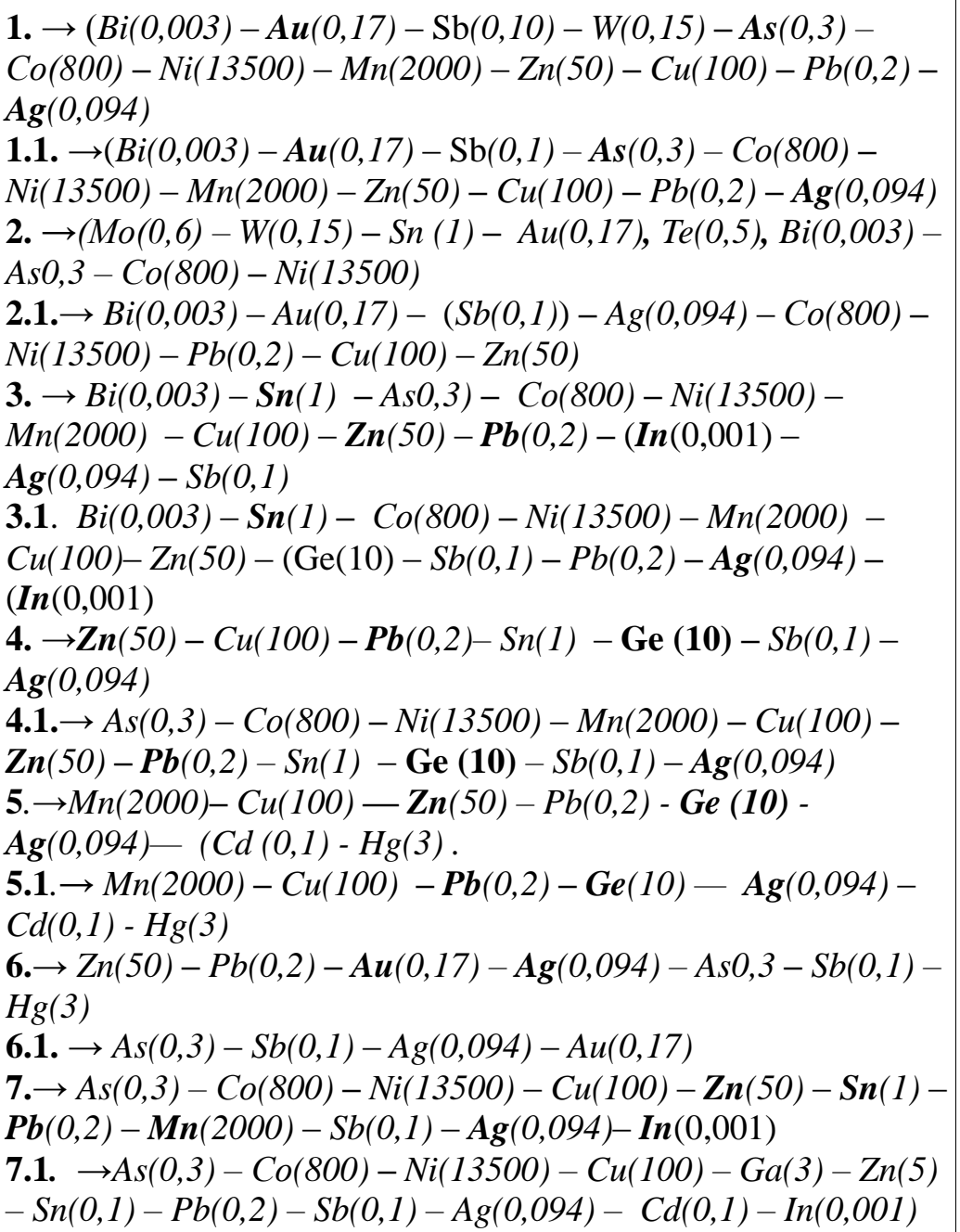 & 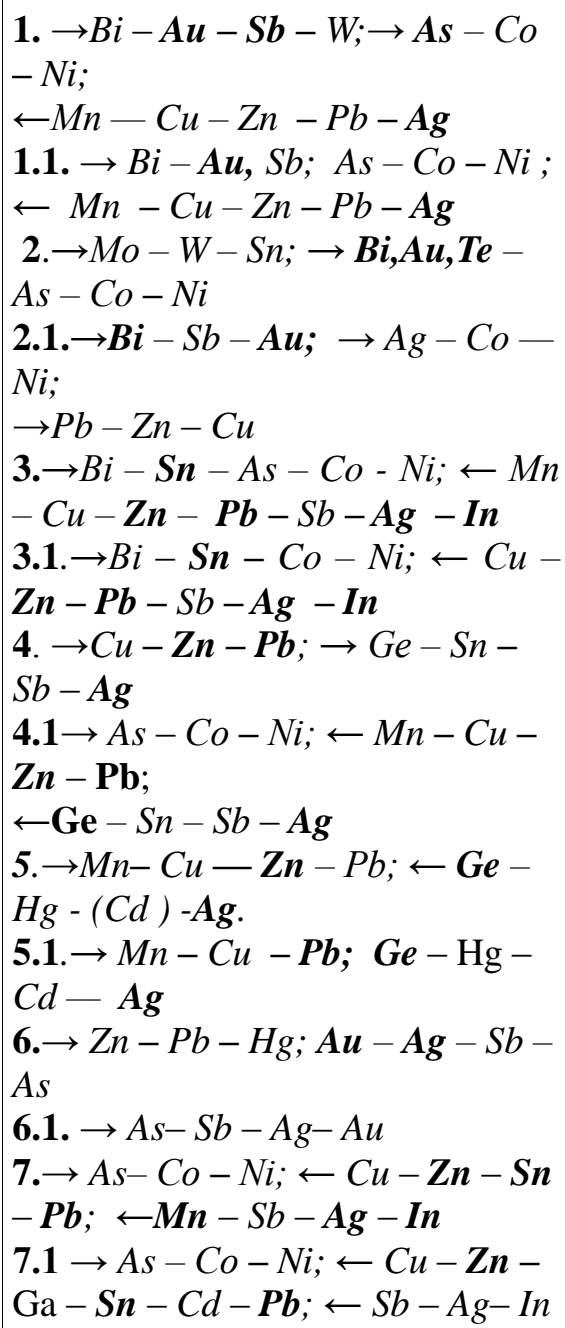 \\
\hline
\end{tabular}

Золотосеребросульфоантимонитовая ассоциация, скрытая в обобщённом эмпирическом ряду зональности, формирует свой ряд, который по направлению вектора зональности является сходным с предыдущим. В ассоциации доминируют сульфосоли $\mathrm{Ag}, \mathrm{Pb}, \mathrm{Sb}$. По минералогическим данным Au и Ag в стадии чаще устанавливаются в срастании с галенитом и сульфосолями свинца, что и определяет их положение в ряду, ранжированном по $\mathrm{S}^{0}{ }_{298}: \leftarrow$ Pb2 $(64,9)-\boldsymbol{A u 3}(47,45)-$
Ag2(42,69) - Sb2(42,44). Порядковыми номерами обозначим принадлежность элементов к этой стадии. Таким образом, в структуре обобщённого эмпирического ряда зональности не устанавливается участие в рудообразовании двухстадийных $\mathrm{Pb}, \mathrm{Ag}$, трёхстадийного - $\mathrm{Au}$ и двухстадийной сурьмы, если не воспользоваться процедурой дополнительного ранжирования эмпирического установленного ряда зональности элементов по величине $\mathrm{S}_{298}^{0}$. 
Таблица 4. Обобщённые и частные геохимические ряды зональности эндогенных рудных месторождений. Элементы ранжированы по распространённости элементов (в скобках) в земной коре [3], г/m (по А.П. Виноградову, 1962)

\begin{tabular}{|c|c|}
\hline Обобщённые ряды геохимической зональности & $\begin{array}{c}\text { Частные ряды геохимической } \\
\text { зональности }\end{array}$ \\
\hline 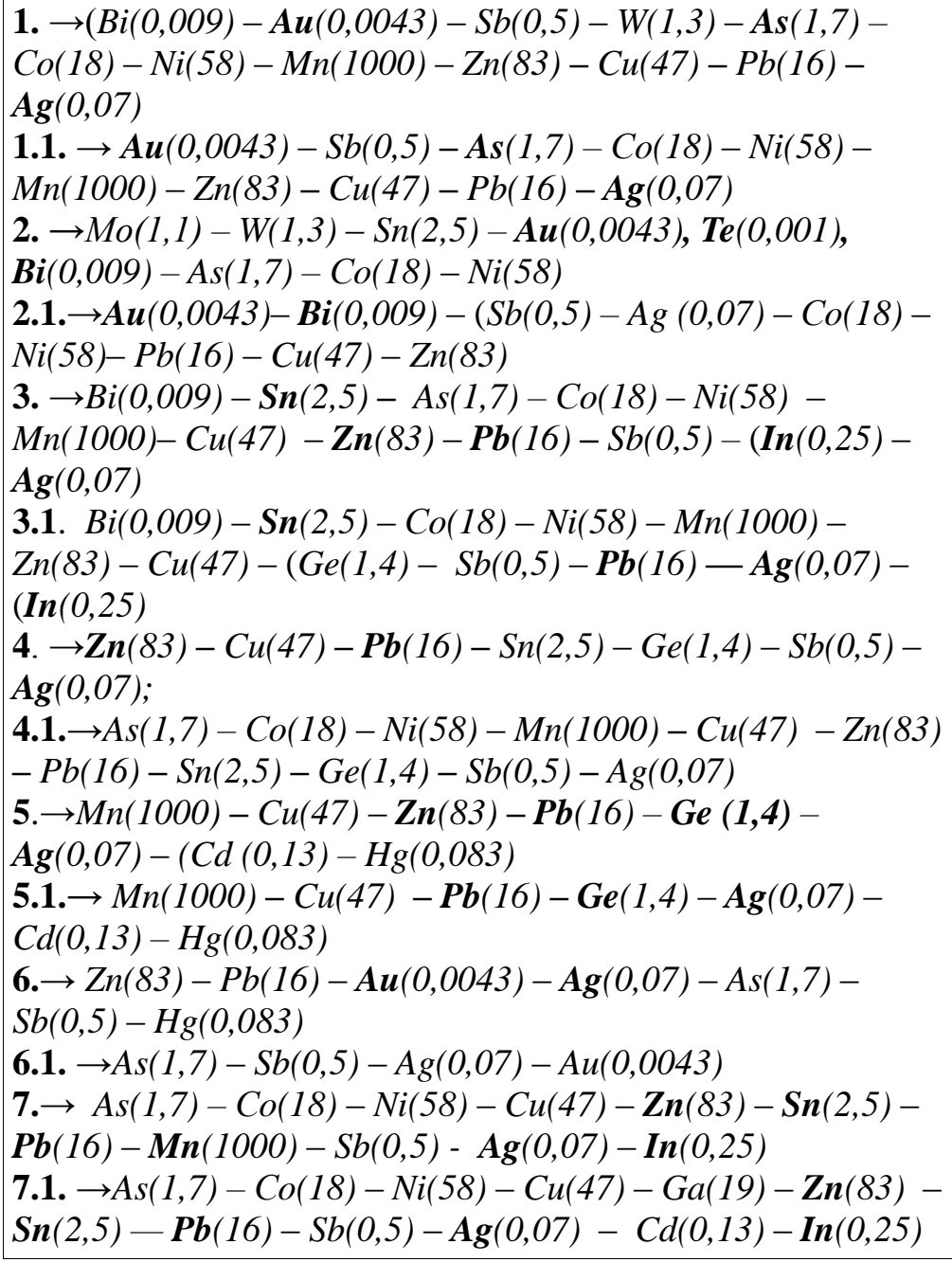 & 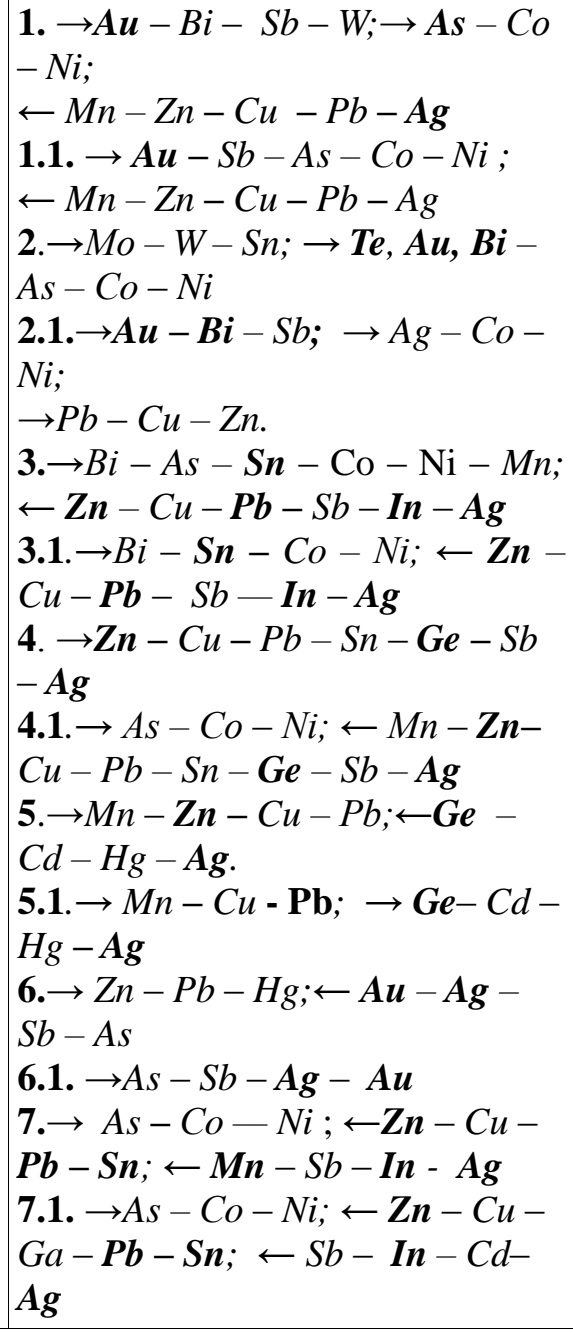 \\
\hline
\end{tabular}

Частные ряды зональности 1 и $\mathbf{1 . 1}$ в табл. 1 приведены без описанной выше процедуры участия элементов в различных стадиях минералообразования, но и в них отражается разнонаправленность векторов зональности во вскрытой сложной динамике рудообразования.

По данным исследования минералогии и геохимии месторождения М.К. Силичевым и Н.В. Белозерцевой впервые были обнаружены промышленные блоки, сформированные по правилу прямой и обратной зональности именно в рамках полисульфидной и сульфоантимонитовой стадий. Задолго до прецизионных изотопных исследований [7], указывающих на наличие в месторождении двух разновозрастных свинцов, был установлен факт привноса части золота из боковых терригенных пород, отличающихся высоким региональным кларком $\mathrm{Au}, \mathrm{As}$ именно в догранитоидную стадию [8].

Зональность золотосеребряной минерализации (ряды 6 и 6.1). Рассмотрена на независимом примере изучения рудномагматических систем Северного Приохотья и зональности, выявленной по примесям в пиритах месторождения Дальнего по материалам [13]. Эти ряды также достаточно хорошо согласуются с обобщён- 
ными и частными эмпирическими рядами, ранжированными по значениям $S_{298}^{0}$ и распространённости их в составе Солнца, хондритах и земной коре. Однако есть нюанс, которой не согласуется с рядом установленной эмпирической зональности рудно-магматической системы. Зональность, установленная Р.Г. Кравцовой по примесям в пирите (6.1), даёт основание усомниться в положении ртути в эмпирическом ряду 6 рудно-магматической системы. Если её положение в ряду изменить (поскольку свойства ртути в ряду $\mathrm{Zn}$ - $\mathrm{Cd}-\mathrm{Hg}$ близки в периодическом законе Д.И. Менделеева) и представить его как $\mathrm{Zn}-\mathrm{Pb}-\mathbf{H g}-\mathrm{Au}-\mathrm{Ag}-\mathrm{Sb}-\mathrm{As}$, то верхняя часть ряда приобретает обратный вектор по отношению к ряду, рассчитанному по примесям пирита, меняя местами $\mathrm{Sb}$ и As в ряду 6. Кстати, $\mathrm{Sb}$ и As, обладающие близкими свойствами в таблице Д.И. Менделеева, также располагаются в одном ряду. Это полностью согласуется с рядом зональности, ранжированным по $S_{298}^{0}$ и рассчитанным Р.Г. Кравцовой для месторождения Дальнего, который в полной мере согласуется со свойствами элементов зонального ряда $\mathrm{As}$ и $\mathrm{Sb}, \mathrm{Ag}$ и $\mathrm{Au}$ в периодическом законе Д.И. Менделеева.

Зональность полисульфидной индийсеребро-олово-свинеи-иинк-марганцевой минерализации. Изучена автором на примере уникальных массивных алабандиновых руд месторождения Высокогорного (Восточная Якутия), представленного многочисленными крутопадающими субмеридиональными секущими жилами, жильными зонами [12]. Локализованы среди позднепермских терригенных пород (обогащённых Mn до 3 - 5 кларков) и риодацитов К1 - К2. Минерализация сформирована в несколько стадий. Ранняя представлена пирит-пирротин-галенит-сфалеритовой с касситеритом и станнином минерализацией, средняя - связана с формированием собственно марганцевой минерализации, на 92 - 98\% состоящей из моносульфида марганца (алабандина) с наличием в ней вкрапленной поздней ассоциации сульфоантимонидов, цинка, свин- ца, меди, олова, серебра, сурьмы и индия. Индий представлен более чем десятком индиевых минералов различной размерности. Концентрации марганца в составе руд от нижних к верхним уровням в жилах варьируют от 49 до $67 \%$, суммы свинца и цинка - до $2 \%$, кадмия - до 7 кг/т, индия от 32 до 1204 г/т [12,19]. Вертикальный размах алабандиновой минерализации в рудном поле установлен в диапазоне 430 м. Минералогическая зональность (по восстанию жил) характеризуется сменой массивных существенно пирит-пирротингаленит-сфалеритовых руд, быстро переходящих в массивные руды с вкрапленной минерализацией алабандина, вплоть до формирования массивных алабандиновых руд в жилах и жильных зонах, прослеживающихся в рудном поле до 6,5 км.

Обобщённые ряды рудно-геохимической зональности установлены по рудным сечениям (7) и примесям в алабандине (7.1). В табл. 2 - 4 те же ряды ранжированы по значениям $\mathrm{S}_{298}^{0}$ и распространённости элементов на Солнце, в хондритах и земной коре.

В частном ряду (7), ранжированном по $\mathrm{S}^{0}{ }_{298}$, проявлены все три стадии в составе основных примесей ранней ассоциации $\mathrm{As}, \mathrm{Co}, \mathrm{Ni}$, средней $-\mathrm{Cu}, \mathrm{Zn}, \mathrm{Sn}, \mathrm{Pb}$ и в поздней - Mn, Sb, Ag, In. В ряду зональности, ранжированном по примесям в алабандине, ситуация не меняется за исключением того, что в частные ряды вклиниваются примеси галлия и кадмия, которые невозможно было выявить в результате расчёта зональности по рудным сечениям. В рядах, ранжированных по распространённости элементов на Солнце и в земной коре, меняются местами $\mathrm{Cu}$ и $\mathrm{Zn}$, что, очевидно, связано с неточной оценкой их кларков, поскольку ранжированием по величине стандартной энтропии и по распространённости в хондритах их положение не нарушается.

Отметим другую важную особенность структуры частного ряда 7.1. Элементы второй и третьей стадий минералообразования образуют ассоциацию $\mathrm{Zn}, \mathrm{Cu}, \mathrm{Ga}$, $\mathrm{Cd}$, In, Ag, располагающуюся в таблице 
Д.И. Менделеева в 5, 7-м рядах и 1,2,3-й группах. Третья особенность состоит в том, что если ранняя ассоциация элементов As, Co, Ni формирует ряд в направлении уменьшения энтропии элементов, то зональный ряд ассоциации элементов средней и поздней стадий, напротив, - в направлении повышения их энтропии. Такое состояние формирования рядов прямой и обратной зональности может быть связано с влиянием как различных источников металлов при формировании руд, так и с влиянием разнонаправленных (прямых или обратных) многостадийных процессов, с изменением как термодинамических, так и физико-химических параметров рудоформирующих систем.

Анализ частных и обобщённых рядов рудно-геохимической зональности изученных месторождений и проявлений даёт возможность выделить некоторые особенности их структуры. А именно: вне зависимости от типов месторождений во многих из них выделяются ассоциации, образующие одинаковые или близкие кластеры: $\mathrm{Bi}-\mathrm{Sb}-\mathrm{As} ; \mathrm{As}-\mathrm{Co}-\mathrm{Ni} ; \mathrm{Mn}-\mathrm{Cu}-$ $\mathrm{Zn}-\mathrm{Pb} ; \mathrm{Sb}-\mathrm{As}-\mathrm{Ag}$; $\mathrm{Au}-\mathrm{Ag}$; с нюансами: $\mathrm{Ge}-\mathrm{Sn}-\mathrm{Pb} ; \mathrm{Ga}-\mathrm{In} ; \mathrm{Cu}-\mathrm{Zn}-\mathrm{Ga}-$ $\mathrm{Ge}$, которые могут быть вложены друг в друга или образовывать синтетические структуры рядов [11], сообразуясь со свойствами элементов в периодическом законе Д.И. Менделеева.

\section{Выводы}

1.Ряды рудно-геохимической зональности полигенных и полихронных эндогенных месторождений могут формироваться под влиянием однонаправленных (одностадийных) или разнонаправленных (прямых или обратных) многостадийных процессов с изменением как термодинамических, так и физико-химических параметров рудоформирующих систем. Это приводит к появлению разных рудных минеральных ассоциаций с разным примесным составом, которые могут быть пространственно (в рудных телах и месторождении в целом) разобщены или совме- щены. Причины дискретно-волнового (прогрессивного или регрессивного) механизма формирования блоков с векторами прямой и обратной зональности в рудных телах могут быть разные: структурнотектонические, изменение РТС-условий в ходе рудообразования, структурнотекстурные особенности самой рудовмещающей среды, эволюция самих источников рудообразования и др.

2.Информация о косвенном влиянии различных процессов на рудообразование может быть установлена при новом ранжировании элементов в составе эмпирически установленных обобщённых рядов рудно-геохимической зональности месторождения по одному или совокупности нескольких фундаментальных показателей, например, стандартной энтропии $\mathrm{S}^{0}{ }_{298}$, относительной распространённости элементов (кларков) на Солнце, в хондритах, земной коре, которые разбивают эмпирические ряды на частные в строгом соответствии с влиянием во времени различных факторов на рудообразование и могут быть сопоставимы с минеральными стадиями. Если ряд эмпирически установленной рудно-геохимической зональности элементов полностью согласуется с рядом, ранжированным по одному или нескольким вышеотмеченным показателям, то рудообразование происходило в рамках единого этапа и одной стадии рудообразования. Если не согласуется, то руды месторождения формировались во столько стадий, сколько разрывов рудогенных ассоциаций элементов обнаруживается в составе эмпирически установленного обобщённого ряда рудно-геохимической зональности. При этом наиболее чувствительным методом выделения частных рядов в обобщённых рядах рудногеохимической зональности является зональность, установленная по примесям сквозных минералов стадий рудообразования.

3. Наличие пространственно совмещенных стадий минералообразования накладывает ограничения на возможность оценки глубинного прогноза любого эндо- 
генного оруденения с использованием обычного метода расчёта рудногеохимической зональности по относительной величине коэффициента накопления элементов с выбором индикаторных отношений уровня вскрытия месторождения, поскольку низ одной продуктивной стадии может совпадать с верхом другой, содержащей искомый элемент прогноза, и т.д.

4.Поскольку при ранжировании элементов в эмпирически установленных рядах рудно-геохимической зональности сохраняется та же последовательность относительно их распространённости на Солнце, то причина сохранения такой закономерности может быть связана не только с фундаментальными термодинамическими свойствами элементов (например, стандартной энтропии, энергии Гиббса и т.д.), но с порядком и периодичностью синтеза ядер химических элементов в звёздах.

5.Вне звёзд во времени и пространстве в последующих процессах химической, физико-химической дифференциации вещества относительная распространённость атомов химических элементов сохраняется на разном уровне его организации: в метеоритах, земной коре, рудах, примесях минералов и не может быть изменена, поскольку это изменение касается только электронных оболочек атомов, но не самих ядер атомов. Эта распространённость может быть изменена только под влиянием ядерных процессов, например, радиоактивности.

6.На основе п. 5 можно постулировать положение, что отношения средних концентраций атомов элементов вне зависимости от уровня организации вещества будут сохранять примерно тот же порядок, который заложен при синтезе их ядер в звёздах.

7.Химические элементы в рядах рудногеохимической зональности могут группироваться в ассоциации (кластеры) с близкими свойствами структуры периодического закона Д.И.Менделева.

\section{Библиографический список}

1. Барсуков В.Л., Григорян С.В., Овчинников Л.Н. Геохимические методы поисков рудных месторождений. М.: Наука, 1981. 347 c.

2. Белозериева Н.В., Кокин А.В., Силичев М.К. Основные принципы прогнозирования и оценки золотого оруденения в терригенных толщах// Геология, методы поисков и разведки месторождений металлических полезных ископаемых / ВИЭМС. М., 1987. Вып. 2. С. 7-12.

3. Войткевич Г.В., Кокин А.В., Мирошников A.Е. Прохоров В.Г. Справочник по геохимии. М.: Недра, 1990. 480 с.

4. Гамянин Г.Н. О прерывистости процесса минералообразования в месторождениях золото-кварцевой формации// Рудообразование и его связь с магматизмом. М.: Наука, 1972. С. 203-214.

5. Гамянин Г.Н., Бортников Н.С., Алпатов B.B. Нежданинское золоторудное месторождение - уникальное месторождение Северо-Востока России. М.: ГЕОС, 2000. 227c.

6. Григорьев Н.А. О кларковом содержании химических элементов в верхних частях континентальной коры// Литосфера. 2002. №1. C. 61-71.

7. Кокин А.В. Новые данные по золотоносности осадочных пород юго-восточного обрамления Сибирской платформы // ДАН CССР. 1990. Т.313, № 3. С. 697-699.

8. Кокин А.В. Эволюция источников металлов при формировании эндогенных рудных месторождений (на примере рудной провинции Юго-Восточной Якутии): докт.дис. Новосибирск, 1990. 300 с.

9. Кокин A.B. Ряды минералогической зональности в структурах Южного Верхоянья (Якутии) // Зап. Всесоюз. мин. об-ва. 1999. T.128, №2. C.12-23.

10. Кокин А.В. Оценка перспективности рудных объектов. Ростов-на-Дону: Ростиздат, $2005.383 \mathrm{c}$.

11. Кокин А.В., Силаев В.И., Батурин А.Л. Алабандин Якутии - новый минеральный тип промышленного оруденения марганца. Ростов-на-Дону: Ростиздат, 2011. 208 с.

12. Кравиова Р.Г. Геохимия и условия формирования золото-серебряных рудномагматических систем северного Приохотья: автореф. докт. дис. Иркутск, 2005. 23 с.

13. Краткий справочник физико-химических величин / под ред. К.П. Мишенко и А.А. 
Равделя. Л.: Химия, 1974. 200 с.

14. Ронов А.Б., Ярошевский А.А., Мигдисов A.A. Химическое строение земной коры и геохимический баланс главных элементов. М.: Наука, 1990. 180 с.

15. Рундквист Д.В., Неженский И.А. Зональность эндогенных месторождений. М.: Недра, $1975.182 \mathrm{c.}$

16. Силичев М.К. Зональность распределения примесей в кварцах, арсенопиритах и галенитах золоторудного месторождения // Геохимия. 1981. №3. С. 379 - 385.

17. Чернышов И.В., Бортников Н.С., Чугаев A.B. $и$ дp. Источники металлов крупного орогенного Нежданинского золоторудного месторождения (Якутия, Россия): результаты высокоточного изучения изотопов свинца (MC - ICP-MS) и стронция // Геология рудных месторождений. 2011. Т.53, №5. C. $395-418$.

18. Ярошевский А.А. Геохимия и ее проблемы (рубеж XX-XXI веков). М.: Изд-во МГУ, $2012.52 \mathrm{c}$.

19. Silaev V.I., Piskunova N.N., Lutoev V.P., Kokin A.V., Kiseleva D.V. New potentially industrial type of indium sulfide-manganese ore // Indium: Properties, Technological Applications and Health Issues. 2013. New York. C. 261-284.

\title{
Ore-geochemical Zonation of Endogenous Mineral Deposits as a Consequence of the Occurrence, Periodic Order and Thermodynamic Properties of Elements
}

\author{
A.V. Kokin \\ South-Russian Institute of Management of Russian Presidential Academy of Na- \\ tional Economy and Public Administration, 70 Pushkinskaya Str., Rostov-on- \\ Don 344000, Russia \\ E-mail: alex@avkokin.ru
}

In the article, the results of investigation of ore-geochemical zonation of endogenous deposits of the Northeast of Russia are presented. It was found that the spatiotemporal zonation of polygenic and polychronous deposits might be generated according the rule of the forward or inverse stage zoning, and is governed by the distribution of chemical element in the Sun, chondrites, and Earth's crust. The order of elements in a zoning sequence remains similar at ore composition and impurities in ore and minerals. Based on determination of secondary series of zoning into the empirically found generalized series for deposit, direct and inverse problems of the presence or absence of superimposed processes of mineralization can be solved, as well as contribution of different sources of metals can be revealed.

Keywords: endogenous deposits, geochemical zoning of ore, mineral phase, the impurities of the minerals, the prevalence of elements, standard entropy, Sun chondrites, Earth's crust.

\section{References}

1. Barsukov V.L., Grigoryan S.V., Ovchinnikov S.V. 1981. Geokhimicheskie metody poiskov rudnykh mestorozhdeniy [Geochemical methods of mineral deposits exploration]. Nauka, Moskva, p. 347. (in Russian)

2. Belozertseva N.V., Kokin A.V., Silichev M.K.
1987. Osnovnye printsipy prognozirovaniya i otsenki zolotogo orudeneniya $\mathrm{v}$ terrigennykh tolshchakh [Basic principles of forecasting and evaluation of gold mineralization in terrigenic strata]. Geologiya, metody poiskov i razvedki mestorozhdeniy metallicheskikh poleznykh iskopaemykh. VIEMS, Moskva, 2:7-12. (in Russian) 
3. Voytkevich G.V., Kokin A.V., Miroshnikov A.E., Prokhorov V.G. 1990. Spravochnik po geokhimii [Guidebook on Geochemistry]. Nedra, Moskva, p. 480. (in Russian)

4. Galyamin G.N. 1972. O preryvistosti protsessa mineraloobrazovaniya $\mathrm{v}$ mestorozhdeniyakh zoloto-kvartsevoy formatsii [About discontinuity of mineralogenesis in the gold-qurtz deposits]. In Rudoobrazovanie i ego svyaz s magmatizmom. Nauka, Moskva, pp. 203-214. (in Russian)

5. Galyamin G.N., Bortnikov N.S., Alpatov V.V. 2000. Nezhdaninskoye zolotorudnoye mestorozhdenie - unikalnoye mestorozhdenie Severo-Vostoka Rossii [Nezhdaninskoye gold deposit: unique deposit of the Northeast of Russia]. GEOS, Moskva, p. 227. (in Russian)

6. Grigoriev N.A. 2002. O klarkovom soderzhanii khimicheskikh elementov $\mathrm{v}$ verkhnikh chastyakh kontinentalnoy kory [About Clarke values of chemical elements in upper parts of continental crust]. Litosfera, 1:61-71. (in Russian)

7. Kokin A.V. 1990. Novye dannye po zolotonosnosti osadochnykh porod Yugo-Vostochnogo obramleniya Sibirskoy platform [New data about gold content of sedimentary rocks of south-east margins of the Siberian Platform]. Doklady AN SSSR. 313(3):697-699. (in Russian)

8. Kokin A.V. 1990. Evolutsiya istochnikov metallov pri formirovanii endogennykh rudnykh mestorozhdeniy (na primere rudnoy provintsii Yugo-Vostochnoy Yakutii) [Evolution of metal sources during formation of endogenic mineral deposits on example of South-East Yakutiya ore province]. Diss. Dr. Sci., Novosibirsk, p. 300. (in Russian)

9. Kokin A.V. 1999. Ryady mineralogicheskoy zonalnosti v strukturakh Yuzhnogo Verkhoyaniya [Mineral zonation series in structures of the south Verkhoyanie]. ZVMO. 128(2):12-23. (in Russian)

10. Kokin A.V. 2005. Otsenka perspektivnosti rudnykh obyektov [Assessment of mineral objects potential]. Rostizdat, Rostov-na-Donu, p. 383. (in Russian)

11. Kokin A.V., Silaev V.I., Baturin A.L. 2011. Alabandin Yakutii - novyy mineralnyy tip promyshlennogo orudeneniya margantsa [Yakutian alabandine as a new mineral type of economic manganese mineralization]. Rotiz dat, Rostov-na-Donu, p. 208. (in Russian)

12. Kravtsova R.G. 2005. Geokhimiya i usloviya formirovaniya zoloto-serebryanykh rudnomagmaticheskikh sistem severnogo Priokhotya [Geochemistry and formation conditions of gold-silver mineral magmatic systems of the north Priokhotie]. Ref. Diss. Dr. Sci., Irkutsk, p. 23. (in Russian)

13. Kratkiy spravochnik fiziko-khimicheskikh velichin [Summary guide on physico-chemical values]. Mishenko K.P., Ravdel A.A. (Eds.). Khimiya, Leningrad, 1974, p. 200. (in Russian)

14. Ronov A.B., Yaroshevskiy A.A., Migdisov A.A. 1990. Khimicheskoe stroenie zemnoy kory i geokhimicheskiy balans glavnykh elementov [Chemical composition of the Earth crust and geochemical balance of the main elements]. Nauka, Moskva, p. 180. (in Russian)

15. Rundkvist D.V., Nezhenskiy I.A. 1975. Zonalnost endogennykh mestorozhdeniy [Zonation of the endogenic deposits]. Nedra, Moskva, p. 182. (in Russian)

16. Silichev M.K. 1981. Zonalnost raspredeleniya primesey $\mathrm{v}$ kvartsakh, arsenopiritakh i galenitakh zolotorudnogo mestorozhdeniya [Zonation of impurities distribution in quartz, arsenopyrite, and galena of the primary gold deposit]. Geokhimiya. 3:379 - 385. (in Russian)

17. Chernyshov I.V., Bortnikov N.S., Chugaev A.V. et al. 2011. Istochniki metallov krupnogo orogennogo Nezhdaninskogo zolotorudnogo mestorozhdeniya (Yakutiya, Rossiya): resultaty vysokotochnogo izucheniya izotopov svintsa (MC - ICP-MS) i strontsiya [The sources of metals of large orogenic Nezhdaninskoye gold deposit (Yekutiya, Russia): results of high-accuracy study of izotopes of lead (MC ICP-MS) and strontium]. Geologiya rudnykh mestorozhdeniy. 53(5):395-418. (in Russian)

18. Yaroshevskiy A.A. 2012. Geokhimiya i eyo problemy (rubezh XX-XXI vekov) [Geochemistry and its problems (XX-XXI century border)]. MGU, Moskva, p. 52. (in Russian)

19. Silaev V.I., Kokin A.V., Kiseleva D.V., Piskunova N.N., Lutoev V.P. 2013. New potentially industrial type of indium sulfidemanganese ore. In Indium. Properties, Technological Applications and Health Issues. Hsaio G. Woo, Huang Tsai Choi (Eds.). Nova Science Publishers, New York. p. 261-272 